\title{
AVALIAÇÃo COMO AUTORREGULAÇÃO dOCENTE NOS PROCESSOS DE ENSINO E DE APRENDIZAGEM: UM OLHAR DO GRUPO GEPES/UNIVALI
}

\author{
EVALUATION AS TEACHING SELF-REGULATION IN THE TEACHING AND LEARNING \\ PROCESSES: THE LOOK OF GEPES/UNIVALI GROUP \\ LA EVALUACIÓN COMO AUTORREGULACION DE LA DOCENCIA EN LOS PROCESOS DE \\ ENSEÑANZA Y APRENDIZAJE: BAJO LA VISION DEL GRUPO GEPES/UNIVALI
}

\section{Yára Christina Cesário Pereira ${ }^{1}$ \\ Kátia Naomi Kuroshima ${ }^{2}$ \\ Marlete dos Santos Dacoreggio ${ }^{3}$ \\ Sueli Petry da Luz ${ }^{4}$}

\section{RESUMO}

Este artigo trata de relatos de experiências do grupo GEPES/UNIVALI sobre a autorregulação da prática docente, por meio da avaliação de estratégias utilizadas no Ensino Superior. O objetivo geral foi revelar a autorregulação da prática docente a partir da avaliação das estratégias de ensino, no Ensino Superior. De um modo geral, justifica-se o estudo pela necessidade de se ampliar os conhecimentos sobre a temática e a urgência em se avançar em concepções e propósitos de como reconhecer a avaliação como processo interdependente da autorregulação da prática docente. A metodologia utilizada foi a narrativa. O plano de desenvolvimento deste trabalho envolveu duas partes: a primeira situa a avaliação na referida área e a autorregulação nos processos de ensino e de aprendizagem e, a segunda descreve experiências sobre avaliação como autorregulação docente do processo de aprendizagem do grupo GEPES/UNIVALI. Os resultados demonstraram que a avaliação das diversas ações e estratégias diversificadas, diferentes e criativas, oportunizou a autorregulação da prática docente, bem como, contribuiu significativamente para a autoavaliação dos acadêmicos sobre as experiências, propiciando ajustes e melhorias nas disciplinas com resultados significativos visíveis e de transformação a cada novo semestre em que as professoras ministraram a disciplina.

PALAVRAS-CHAVE: Autorregulação docente. Avaliação. Ensino superior. Experiências pedagógicas.

\begin{abstract}
This article is about reports of experiences of the GEPES / UNIVALI group on the self - regulation of teaching practice, through the evaluation of strategies used in Higher Education. The main objective was to reveal the self-regulation of teaching practice from the evaluation of teaching strategies in Higher Education. In general, this study is justified by the necessity to expand knowledge about these subject and the urgency of advancing conceptions and purposes of how to recognize evaluation as an interdependent process of self-regulation of teaching practice. The methodology used was narrative. This article is presented in two parts: the first shows the evaluation in that area and the self-regulation in the teaching and learning processes, and the second, describes experiences on evaluation as teacher self-regulation of the learning process of the GEPES / UNIVALI group.
\end{abstract}

\footnotetext{
${ }^{1}$ Pós-doutora em Educação Ambiental pela Universidade Federal do Rio Grande. Doutora em Educação pela Universidade Federal de Santa. Professora titular da Universidade do Vale do Itajaí. E-mail: yara@ univali.br ORCID: http://orcid.org/0000-0002-6502-1860.

${ }^{2}$ Doutora em Química (área de Química Orgânica) pela Universidade Federal de Santa Catarina. Professora da Universidade do Vale do Itajaí. E-mail: kuroshima@univali.br - ORCID: http://orcid.org/0000-0002-4261-9878

${ }^{3}$ Doutora em Educação pela Universidade Federal de Santa Catarina. Professora titular da Universidade do Vale do Itajaí e da Faculdade Sinergia/Navegantes-SC. E-mail: marlete54@gmail.com - ORCID: http://orcid.org/0000-0003-2936-1961

${ }^{4}$ Doutora em Educação pela Universidade Estadual de Campinas. Coordenadora do curso de Pedagogia e chefe de Departamento no Centro de Ensino Superior, da Universidade Regional de Chapecó (SC). E-mail: petryluz@univali.br - ORCID: http://orcid.org/0000-0001-7793-6454
}

Submetido em:30/11/2016 - Aceito em: 08/12/2016

\begin{tabular}{l|l|l|l|l|l|l}
\hline (C) Rev. Inter. Educ. Sup. & Campinas, SP & v.2 & n.3 & p.532-551 & set./dez. 2016 & ISSN 2446-9424
\end{tabular}


The results showed that the evaluation of diverse actions and diversified strategies, different and creative, allowed the self-regulation of the teaching practice, as well as, contributed significantly to the self-evaluation of the students on the experiences, providing adjustments and improvements in the disciplines with visible and significant results visible and transforming each new semester in which the teachers taught the discipline.

KEYWORDS: Self-regulation of teaching. Evaluation. Higher education. Pedagogical experiences.

\section{RESUMEN}

Este articulo trata de informes de las experiencias del grupo GEPES/UNIVALI sobre la autorregulación de la práctica de la enseñanza por medio de evaluación de las estrategias utilizadas en la Educación Superior. El objetivo general fue revelar la autorregulación de la práctica de la docencia a partir de la evaluación de las estrategias de enseñanza en la Educación Superior. En general, el estudio se justifica por la necesidad de incrementar los conocimientos sobre el tema y la urgencia en avanzar en nuevos conceptos y propósitos de como reconocer la evaluación como un proceso interdependiente de la autorregulación de la práctica de la enseñanza. La metodología utilizada fue la narrativa. El plan de desarrollo de este trabajo consistió en dos partes: la primera aborda la evaluación en el área citada, y la autorregulación en los procesos de la enseñanza y del aprendizaje, la segunda describe las experiencias de la evaluación como forma de autorregulación de la docencia en el proceso de aprendizaje del grupo GEPES/UNIVALI. Los resultados muestran que la evaluación de las diversas acciones y estrategias, diferentes y creativas, ha proporcionado la oportunidad de trabajar con la autorregulación de la práctica docente, contribuyendo de forma significativa en la autoevaluación de los académicos sobre las experiencias, proporcionando ajuste y mejoras en las asignaturas con resultados significativos visibles y de transformación de cada nuevo semestre en el cual los profesores participaron impartiendo clases.

PALABRAS CLAVE: Autorregulación de la docencia. Evaluación. Educación superior. Experiencias educativas.

\section{Introdução}

Este artigo trata de relatos de experiências do grupo GEPES/UNIVALI sobre a autorregulação da prática docente, por meio da avaliação de estratégias utilizadas no Ensino Superior.

Assim, teve como objetivo geral revelar a autorregulação da prática docente a partir da avaliação das estratégias de ensino, no Ensino Superior. Para o alcance deste objetivo, foram definidos como específicos: (a) situar a avaliação na amplitude da área e nos diferentes significados; (b) identificar os procedimentos da autorregulação docente nos processos de ensino e de aprendizagem; (c) descrever experiências das pesquisadoras do referido grupo sobre avaliação como autorregulação docente nos processos de ensino e de aprendizagem, no Ensino Superior.

As justificativas que demandaram a elaboração do artigo foram: (a) a necessidade de se ampliar os estudos sobre a temática; (b) o fato da bibliografia sobre o tema evidenciar, por um lado, estudos focados no processo de avaliação sob seus diversos aspectos, mas, deixar a desejar o uso da autorregulação na prática docente; (c) a urgência em se avançar em concepções e propósitos de como reconhecer a avaliação como processo interdependente da autorregulação da prática docente; (d) a valorização da autorregulação nos processos de ensino e de aprendizagem pela Instituição estimulando a escrita de experiências docentes neste sentido. 
O plano de desenvolvimento deste trabalho envolve duas partes: a primeira situa a avaliação na referida área e a autorregulação nos processos de ensino e de aprendizagem e, a segunda descreve experiências sobre avaliação como autorregulação docente do processo de aprendizagem do grupo GEPES/UNIVALI (KUROSHIMA et al., 2016).

\section{A Avaliação na Amplitude da Área e Autorregulação Docente nos Processos de Ensino e de Aprendizagem}

A área de avaliação é uma fonte inesgotável de estudos, discussões e possui um amplo campo que necessita de contextualização e de respostas para delimitação da temática que está sendo trabalhada, como por exemplo: O que é avaliação? Quais as funções/modalidades de avaliação que está sendo focada? Que concepção ou geração de avaliação estamos falando? Em que tipo de avaliação se classifica o artigo? Qual o nível de ensino que se situa? Qual a finalidade da avaliação que está sendo efetuada? Que modalidade de avaliação está sendo praticada? Que interpretações podemos atribuir à avaliação? Que significa autorregulação do processo ensino-aprendizagem? Que procedimentos são requeridos na avaliação como autorregulação docente nos processos de ensino e de aprendizagem?

Na busca de respostas à questão de conceituação pode-se dizer que avaliar provém do latim $a+$ valere que significa atribuir valor e mérito ao objeto em estudo. Leva em conta uma decisão de ação, uma tomada de posição, segundo Luckesi (1995), UNIVALI (2001) e Vale (2016). Ele foi criado há, aproximadamente, uns cinquenta anos e, desde então, tem sido objeto de estudo e transformações conceituais (VALE, 2016). Analisando em termos históricos, pode-se afirmar que existem várias funções e gerações de avaliação. Nesse sentido, tem-se três funções/modalidades da avaliação que são: diagnóstica, formativa e a somativa.

Objetivando delimitar a problemática, o foco selecionado abrange a avaliação formativa, que será abordada do ponto de vista do docente, e não do aluno, como comumente é trabalhada. Geralmente, a avaliação como possibilidade de autorregulação do processo de aprendizagem é focada na autoavaliação do acadêmico, que em algumas experiências das pesquisadoras até ela faz parte, mas esse não será o foco neste artigo.

$\mathrm{Na}$ temática em questão, a expressão avaliação formativa tem uma finalidade pedagógica direcionada ao professor, visando contribuir para o aprimoramento da aprendizagem dele numa disciplina específica de um curso selecionado. Visa o aperfeiçoamento das ações e processos no meio de uma disciplina ou que possibilita coletar dados ao final dela para melhoria do percurso a ser efetuado no semestre seguinte.

Tendo por base Miranda, Sobreiro, Vergílio (2003), os estudiosos citados em Borges et al. (2014); pesquisadores apresentados em Sá, Alves, Costa (2014); Borges (2015); Costa (2015) e Serpa (2015) pode-se afirmar que a avaliação formativa apresenta algumas características que são peculiares ao aluno, mas que no caso em questão da temática, também,

\begin{tabular}{l|l|l|l|l|l|l} 
(C) Rev. Inter. Educ. Sup. & Campinas, SP & v.2 & n.3 & p.532-551 & set./dez. 2016 & ISSN 2446-9424
\end{tabular}


podem ser transpostas ao professor. Os autores em questão abordam que ela:

a) É contínua, pois ocorre em diferentes momentos dos processos de ensino e de aprendizagem.

b) É informal e dialógica em razão de ocorrer durante todas as oportunidades de interação entre professor e aluno.

c) Verifica o grau de aprendizagem do professor para possíveis ajustes, tendo em vista a temática escolhida.

d) Estimula a autoavaliação e autorregulação da aprendizagem docente.

e) Constitui uma atividade reguladora do processo de ensino e de aprendizagem, detectando lacunas e possíveis soluções para os obstáculos.

f) Há corresponsabilidade do professor e aluno. Ao aluno, possibilita emitir opinião sobre o percurso e a aprendizagem efetuada, permitindo que ele contribua com ajustes e correções na disciplina. Ao professor aperfeiçoa a prática docente, passando a trabalhar melhor a partir das avaliações efetuadas, reorientando percursos ou etapas das atividades.

Perrenoud (1999, p. 89) observa que a ideia de avaliação formativa leva

[...] o professor a observar mais metodicamente os alunos, a compreender melhor seus funcionamentos, de modo a ajustar de maneira mais sistemática e individualizada suas intervenções pedagógicas e as situações didáticas que propõe, tudo isso na expectativa de otimizar as aprendizagens.

As concepções ou gerações que norteiam a avaliação, segundo Fernandes (2005), são diversificadas e classificam-se como: avaliação como medida, avaliação como descrição, avaliação como juízo de valor e avaliação como negociação ou construção social. O autor mais referenciado para situar a classificação das quatro gerações de avaliação é Guba e Lincoln (1989, citado por MIRANDA; SOBREIRO; VERGÍlLIO, 2003) e reafirmado por Firme (1994, destacada, também, por BORBA, FERRI,1999; UNIVALI, 2001), que já foram ampliadas e atualizadas com outros autores a seguir discriminados, como por exemplo: Kraemer (2005); Haydt (2006); Borba, Ferri, Hostins (2007); e Depresbiteris (2016). Buscando simplificar e delimitar a temática, trabalha-se, somente, a avaliação como negociação ou construção social, já resumida por Luz e Borba (2015).

$\mathrm{Na}$ avaliação como negociação ou construção social identificam-se as seguintes explicações: estar integrada no processo de ensino e aprendizagem; primar pela relevância dos contextos, da participação, da interação, da negociação, do envolvimento dos alunos nos processos de construção social do conhecimento e dos processos cognitivos, sociais e culturais na sala de aula; focalizar a avaliação formativa, como modalidade privilegiada de avaliação, visando melhorar e regular a aprendizagem; dar relevância e primazia ao feedback; avaliar para apoiar o desenvolvimento das pessoas; enfatizar os métodos qualitativos, sem descurar dos quantitativos; ajudar a pessoa a desenvolver a sua aprendizagem, ao invés de julgar ou classificar. O conhecimento vem a ser uma construção social. O papel do professor 
é de ser mediador, cuja preocupação está centrada na gestão do ensino e da aprendizagem dos alunos. Ela exerce um papel ético e político de negociação. Este tipo de professor partilha o poder de avaliar com os alunos. Esta avaliação, então, situa-se numa perspectiva construtivista.

No campo da avaliação pode-se dizer que existem vários tipos, compondo uma espécie de hierarquia de avaliação, conforme Sousa (1999) e Santos Filho (2013), Luz e Borba (2015) a saber: avaliação em nível de sistema, isto é, de instituições de ensino superior: Universidade, Centro Universitário, Faculdades Integradas, Faculdades Isoladas ou Instituições ou Escolas Superiores; avaliação de instituições objetivando o credenciamento ou renovação de credenciamento; avaliação de curso visando o reconhecimento ou renovação de reconhecimento do curso; avaliação de currículo, avaliação de disciplinas, avaliação de programa e projetos, avaliação docente, avaliação discente, avaliação de aprendizagem e outras.

No presente artigo, o foco é a avaliação docente, mas vinculada ao processo de autorregulação nos processos de ensino e de aprendizagem de uma disciplina.

Para situar o tipo de disciplina, no nível de ensino, apresenta-se a sua composição no país, isto é, a Lei 9394/96 (BRASIL, 2016), em seu artigo 21, que regulamenta: I - educação básica, formada pela educação infantil, ensino fundamental e ensino médio; II - educação superior. Neste artigo, o foco do nível trabalhado é o do ensino superior, vinculado à prática docente exercida em diferentes disciplinas e cursos selecionado pelos diferentes pesquisadores do GEPES/UNIVALI.

Dando seguimento às respostas aos questionamentos, a finalidade da avaliação que está sendo efetuada tem em vista a prática de um docente se inserir na trajetória da autorregulação dos processos de ensino e de aprendizagem da prática de ações, processos e procedimentos de uma disciplina do ensino superior, com vistas ao seu aperfeiçoamento e construção de um currículo que potencialize as habilidades cognitivas e a metacognitivas. A metacognição foi um termo cunhado por Flavel (1979) e se refere à autoconsciência dos próprios processos cognitivos, que, no caso em estudo, envolve a colaboração e parceria direta dos acadêmicos. Hadji (2001, p.103) denomina de metacognição "[...] o processo mental interno pelo qual um sujeito toma consciência dos diferentes aspectos e momentos de sua atividade cognitiva".

Nos processos de ensino e de aprendizagem, a metacognição pode desempenhar um papel essencial na elaboração de estratégias desafiadoras que leve professor e aluno a construir e reconstruir seu próprio conhecimento otimizando a cultura do pensar, da resolução de problemas e na gestão de tarefas com autonomia.

Em continuidade à busca de respostas às interpretações sobre avaliação, Fernandes (1994) e Hadji (2001) classificam-nas em avaliação normativa, avaliação de referência criteriada e avaliação prognóstica. A avaliação normativa tem por objetivo situar os

\begin{tabular}{l|l|l|l|l|l|l} 
(C) Rev. Inter. Educ. Sup. & Campinas, SP & v.2 & n.3 & p.532-551 & set./dez. 2016 & ISSN 2446-9424 \\
\hline
\end{tabular}


indivíduos com relação aos outros, enquanto a avaliação de referência criteriada tem como foco um determinado comportamento situando-o em relação a um critério ou objetivo a ser atingido. A avaliação prognóstica tem sentido quando os atores dos processos de ensino e de aprendizagem conseguem identificar o que já sabem (conceitos apropriados), o que 'ainda' não sabem (conceitos em formação) e compreender o seu modo de pensar de forma argumentada. A avaliação passa a ser um instrumento que contribui efetivamente com a regulação das atividades curriculares fornecendo informações para a autorregulação dos sujeitos envolvidos no processo. O foco, por assim dizer do presente artigo, é a avaliação prognóstica.

Para Perrenoud (1991, apud HADJI, 2001), o professor é informado dos efeitos reais de seu trabalho e poderá regular sua ação; terá flexibilidade, vontade de se adaptar, dando vez à variabilidade didática. $\mathrm{O}$ aluno poderá: saber onde anda tomando consciência de suas dificuldades e reconhecer ou corrigir seus próprios erros, qualificando os processos de ensino e de aprendizagem uma vez que permite identificar as correções a realizar, com base no feedback fornecido.

Tendo por base Perrenoud (1999), chega-se à regulação do ensino-aprendizagem como da ação pedagógica que deve possibilitar ao educador redimensionar as trajetórias a serem percorridas desembocando numa prática formativa, no caso em questão, de sua disciplina.

Envolvido numa "regulação proativa", o professor necessita dar encaminhamento de atividades de consolidação e de aprofundamento, de atividades novas e diferentes que possibilitem a compreensão, elaboração e reelaboração dos conceitos pelo aluno, em diferentes contextos e atividades, sejam elas concretas, observáveis, abstratas ou dedutíveis (HADJI, 2001).

Mas, o que se está a buscar na docência da UNIVALI é a autorregulação dos processos de ensino e de aprendizagem que, na busca de conceituação, vem a ser as "[...] capacidades do sujeito para gerir ele próprio seus projetos, seus progressos, suas estratégias diante das tarefas e obstáculos” (PERRENOUD, 1999, p. 96). Ela constitui “[...] um processo intencional do aluno que envolve, de forma inter-relacionada, componentes motivacionais, metacognitivos e comportamentais (VEIGA SIMÃO, 2005), sem as quais não se concretiza o dito processo" (FERREIRA, 2009, p. 3503).

Com relação ao último questionamento, ou seja, os procedimentos requeridos na avaliação como autorregulação docente nos processos de ensino e de aprendizagem, envolvem um (a):

a) Olhar atento e um contínuo processo de atenção dos "sucessos e insucessos" acadêmicos;

b) Registro sistemático envolvendo "ação-reflexão-ação" da prática docente de sala de aula;

c) Fazer ciência em sua disciplina como professor pesquisador;

\begin{tabular}{l|l|l|l|l|l|l} 
(c) Rev. Inter. Educ. Sup. & Campinas, SP & v.2 & n.3 & p.532-551 & set./dez. 2016 & ISSN 2446-9424 \\
\hline
\end{tabular}


d) Disposição e disciplina docente de querer melhorar o seu desempenho pedagógico na disciplina;

e) Aceitação das críticas e sugestões dos acadêmicos, como focos de melhoria do fazer pedagógico;

f) Parceria dialógica, uma interação e participação ativa entre professor e aluno, capaz de influir no processos de ensino e de aprendizagem,

g) Vontade pessoal de sempre estar se reinventando na disciplina que ministra.

Este foi um processo de construção das autoras e que se desenvolveu a partir da açãoreflexão-ação em suas práticas pedagógicas, apresentadas na sequência.

\section{Experiências de Avaliação Como Autorregulação Docente}

A seguir são apresentadas quatro experiências diversificadas referentes à aplicação da avaliação como autorregulação das suas disciplinas nos processos de ensino e de aprendizagem em diferentes cursos universitários. Elas são relatadas pelas próprias professoras pesquisadoras do GEPES/UNIVALI, o que resultou em linguagem e maneira de abordar diferenciadas. A metodologia adotada foi que todos os casos deveriam abranger quatro itens: contextualização, tipo de experiência realizada, metodologia e resultados, cujo foco vinha a ser a temática em estudo.

Nesse sentido: a professora Y selecionou os mapas conceituais como instrumento de avaliação pelo fato de vislumbrar o exercício da metacognição; a professora $\mathrm{K}$ trabalhou os projetos integrados, focando a área específica como elemento desencadeador para a superação das fragilidades conceituais de aprendizagem; a professora $\mathrm{M}$, relatou a simulação da articulação da teoria e prática nas funções do coordenador pedagógico, para melhor compreender do papel desse profissional na escola pública. Finalizando, o relato da professora $\mathrm{S}$ focalizou a ficha de avaliação de final de disciplina como subsídio para a autorregulação docente nos processos de ensino e aprendizagem.

\section{CASO 1-Professora Y}

\section{Contextualização}

A professora $\mathrm{Y}$ apresenta uma estratégia didático-pedagógica que tem sido utilizada como instrumento de avaliação na disciplina Trabalhos Acadêmico-Científicos (TAC), inserida nas matrizes curriculares ( $1^{\circ}$ ou $2^{\circ}$ período) dos cursos de Ciências Biológicas, Engenharia Civil, Oceanografia e Pedagogia, como papel essencial na autorregulação docente nos processos de ensino e de aprendizagem. 


\section{Tipo de Experiência realizada}

A experiência realizada teve por intenção desvelar os conceitos já apropriados pelos acadêmicos (diagnóstico) e os em processo de reelaboração (prognóstico) para sinalizar à professora aspectos relacionados às operações do pensamento que pudessem ser referenciais para reorganização de outras estratégias de aprendizagem, como também, a elaboração do plano de ensino para os semestres seguintes.

Como atividade curricular, o MC propicia a autorregulação dos processos de ensino e de aprendizagem da prática de ações da docente e dos discentes, uma vez que: mobiliza pensamento; potencializa a elaboração conceitual; possibilita o compartilhamento de ideias; a troca de experiências e saberes e o enredamento de conceitos. É uma técnica muito flexível podendo ser usado em diversas situações, para diferentes finalidades: instrumento de análise de currículo; técnica didática; recurso de aprendizagem e meio de avaliação, entre outros. Como estratégia de aprendizagem favorece a identificação dos conceitos prévios dos acadêmicos que poderão auxiliar na organização de outras atividades curriculares. A interrelação de conceitos e ideias, a pesquisa sobre conceitos ainda não apropriados, pode resultar na reconstrução dos conhecimentos (MOREIRA; BUCHWEITZ, 1993).

\section{Metodologia}

Estratégica e metodologicamente, os MCs têm sido elaborados nos laboratórios de informática da UNIVALI, com o uso de ferramentas tecnológicas. Já, os artigos científicos utilizados para o desenvolvimento dos MCs são relacionados à sustentabilidade socioambiental; aos princípios da diversidade; às questões étnico-raciais e conceitos articuladores. Textos em outras disciplinas dos cursos foram utilizados, e num dos cursos fezse uso de Cortella (2008).

A ressignificação conceitual dos acadêmicos proporciona "diferentes olhares" para a professora quanto aos seus próprios significados, uma vez que as temáticas proporcionam "o pensar sobre o seu próprio pensar". Orienta a docente e os discentes a analisarem sua própria rede de conceitos pela diferenciação progressiva e a reconciliação integrativa entre conceitos.

Como instrumento de avaliação utilizou-se de critérios tais como: domínio conceitual; relações justificadas entre os conceitos; argumentação fundamentada; coerência entre as proposições; riqueza de ideias; criatividade na apresentação; clareza e coerência na exposição do tema; lógica na organização; participação de todos os elementos do grupo na exposição do trabalho.

Vale ressaltar que os critérios de avaliação eram negociáveis e dependiam dos objetivos de aprendizagem, bem como estavam relacionados à observação do desenvolvimento das habilidades de compreensão, análise e síntese do conhecimento e não só do conteúdo trabalhado. Durante a elaboração dos MCs, a professora realizou intervenções desafiadoras que fomentaram a discussão individual e coletiva. É nesse momento, que o 
pensar dos acadêmicos se revelou com tal intensidade, que quando estes se posicionaram de forma argumentativa, levaram a professora a reorganizar as atividades curriculares, o que aconteceu com frequência, pelo "embate" de ideias, atitudes, valores e emoções.

As negociações realizadas durante a elaboração do $\mathrm{MC}$ e o diálogo para se chegar num consenso e as representações conceituais, suas e de seus colegas, potencializaram conceitos já apropriados e desvelaram os que ainda não estavam interiorizados em sua estrutura cognitiva.

Incluir os MCs no processo formativo do acadêmico fomenta a negociação de significados - um trabalho metacognitivo que leva a uma aprendizagem significativa. $O$ acadêmico tem a liberdade e a autonomia para representar seus conhecimentos da forma como foram concebidos no seu raciocínio, criando suas próprias estruturas de pensamento. Esta é a riqueza do uso dos MCs.

As fichas de avaliação utilizadas pela professora Y constam no Apêndice A.

\section{Resultados}

Os resultados das vivências dos MCs foram analisados de forma qualitativa e ainda que de forma insuficiente, permitiram inferir que: aproximam, acolhem, aconchegam professora e acadêmicos, numa situação de afetividade e metacognição; permitem reconhecer lacunas ou equívocos conceituais; observar a si próprio, isto é, aprender a pensar; perceber os momentos da necessidade de mediações; desenvolver o pensamento argumentativo; realizar ajustes no plano de ensino em relação a metodologia e conteúdos; efetivar reflexões pessoais a nível de organização e planificação da ação, entre outros.

Para a professora $\mathrm{Y}$, a contribuição de maior relevância foi a percepção de que o conhecimento técnico da disciplina, o conhecimento da experiência e os saberes da docência implicam em observar, refletir, analisar, reorganizar a própria prática desenvolvendo atividades curriculares que contribuam para a conquista ou fortalecimento da autonomia intelectual, sua e dos acadêmicos.

\section{Caso 2 - Professora $K$}

\section{Contextualização}

A avaliação como processo autorregulatório da Professora K aconteceu na disciplina de Oceanografia Química, do terceiro período do Curso de Oceanografia. Este Curso é classificado na área de conhecimento do CNPq em Ciências Exatas e da Terra devido à necessidade dos conhecimentos das áreas de exatas, como matemática, física e química para a formação e atuação profissionalizante. No entanto, muitos alunos não visualizavam essa necessidade e importância, tendo a ilusão deste curso abordar majoritariamente assuntos da área biológica, apresentando desta forma, um elevado grau de desmotivação nas disciplinas destas áreas. 
A Avaliação Institucional, realizada anualmente, categorizava esta disciplina com um dos maiores índices de reprovação no curso, muitas vezes acima de 70\%. Esta disciplina aborda conteúdos de química analítica aplicados à biogeoquímica da água do mar, envolvendo assim, não apenas o conhecimento de química, como também das áreas de matemática e oceanografia. Foi observado também, que, quando os conteúdos envolviam o tema oceanografia, os processos de aprendizagem apresentavam sempre resultados mais positivos, mesmo abordando conteúdos de maior complexidade. Além disso, uma análise qualitativa da docente observou que durante estas aulas, a motivação e o interesse eram maiores.

Outra questão que chamou a atenção da professora foi a falta de compreensão dos alunos em relacionar a aplicação da mesma metodologia analítica para a determinação de parâmetros químicos em diferentes amostras. Nas aulas foram abordados os procedimentos metodológicos para a determinação de parâmetros químicos da água do mar, e as mesmas metodologias poderiam ser aplicadas para amostras biológicas (tecido de peixes, moluscos, folhas, macroalgas) e geológicas, mas dificilmente, os alunos conseguiam fazer essa relação.

As dificuldades de ensino e de aprendizagem na disciplina, a falta de motivação em assuntos puramente químicos, a falta de percepção da multifuncionalidade das metodologias químicas para as diferentes matrizes amostrais por um lado, e por outro, o interesse por assuntos vinculados à oceanografia, e diferentes habilidades dos alunos fizeram a docente repensar nas suas metodologias e estratégias utilizadas nesta disciplina.

\section{Tipo de experiência realizada}

Desta forma, focando nas problemáticas levantadas anteriormente procurou-se juntamente com a disciplina de Ecofisiologia Vegetal, do mesmo período, desenvolver um trabalho interdisciplinar, a priori denominado de "Projeto Integrador". Nesse projeto, os alunos deveriam escolher um tema abordando o uso de metodologias químicas aplicados em amostras de água do mar e adaptar às amostras biológicas ou geológicas; posteriormente, discutir os dados em função de adaptações fisiológicas das plantas sob diferentes condições oceanográficas no ambiente. Dessa forma, este projeto tinha o objetivo de trabalhar as dificuldades dos alunos na área química, mas motivados pelo tema aplicado à oceanografia, buscar a superação. Buscava ainda, trabalhar outros aspectos: o aprendizado através da solução de problemas na prática, o despertar para a pesquisa, a organização de dados, análise e discussão dos resultados, aplicação de metodologias para a elaboração de um trabalho acadêmico científico.

\section{Metodologia}

No primeiro momento foram elaborados diferentes experimentos e os alunos poderiam escolher entre os projetos elaborados pelos professores. Os projetos foram desenvolvidos ao longo de um semestre letivo, envolvendo todas as etapas do desenvolvimento de um projeto de pesquisa: planejamento, coleta de dados, análise e 
discussão dos resultados e elaboração de um documento final. Esses projetos foram desenvolvidos em grupos de 3 alunos, e além do tempo disponibilizado para as aulas, muitas atividades demandaram atividades extraclasse, em função das atividades laboratoriais que foram acompanhados pelos professores e monitores das duas disciplinas, além da necessidade de pesquisa bibliográfica e trabalhos em grupos para a discussão dos dados obtidos e elaboração do relatório final. Ao final do semestre, além das avaliações pertinentes ao desenvolvimento da atividade, foram aplicadas autoavaliações (Apêndice B) e avaliação sobre a atividade, na perspectiva de uma autorregulação docente quanto aos processos de ensino e de aprendizagem desta disciplina.

\section{Resultados}

A aplicação deste projeto, no primeiro semestre, foi bastante positiva, com o envolvimento muito motivador de todos os alunos participantes. Houve reclamação de alguns alunos com relação ao excesso de atividade extraclasse, no entanto, a participação proporcional na composição das notas da disciplina e o resultado apresentaram melhoras significativas em relação aos semestres anteriores, os próprios alunos se mostraram satisfeitos com esta proposta.

A adaptação dos métodos químicos em diferentes amostras e a aplicação de conceitos químicos sobre as amostras ambientais, motivando os alunos, foram os principais resultados observados. Dessa primeira turma, muitos alunos, ficaram tão motivados que deram continuidade ao projeto, como um Projeto de Pesquisa, submetendo posteriormente aos editais institucionais internos de pesquisa, com as devidas adaptações, chegando inclusive à apresentação como trabalho de conclusão de curso.

No entanto, muitos aspectos precisavam ser melhorados na aplicação desse Projeto Integrador, apontados na ficha de autoavaliação discente, além dos registros da professora: redimensionamento das atividades à carga horária da disciplina; possibilidade de trabalhar com outros assuntos além da fisiologia vegetal; excessiva atividade extraclasse aos professores; reorganização de conteúdos e ementas, avaliação ao longo de todo o processo, desde o início do semestre, entre outros. Todos estes itens foram considerados, e regulados semestralmente. Atualmente, a realização dos Projetos Integrados na disciplina é discutida previamente, no primeiro dia de aula. O tema abordado, o cronograma das atividades extraclasse, o peso, critério e calendário de cada avaliação, enfim, todos os aspectos envolvendo a realização do projeto são discutidos exaustivamente e, aplicados somente na concordância da maioria dos alunos. Dependendo da turma, já houve situações em que essa atividade foi substituída por outras estratégias, e quando isso aconteceu, o principal motivo foi o excesso de atividade extraclasse. 


\section{Caso 3: Professora $M$}

\section{Contextualização}

A experiência da professora $M$ aconteceu por meio do projeto ARTICULAÇÃO TEORIA/PRÁTICA NAS FUNÇÕES DO COORDENADOR PEDAGÓGICO, no $8^{\circ}$ período do curso de Pedagogia de uma Faculdade privada, do Vale do Itajaí.

\section{Tipo de experiência realizada}

Tratou-se de uma atividade trabalhada desde 2010, com dez turmas de formandas de um curso de Pedagogia. O objetivo principal do Projeto, desde a primeira versão, foi vivenciar a prática do trabalho do Coordenador Pedagógico (CP) para melhor compreensão do papel deste profissional na escola pública. Justificou-se o respectivo projeto pelo desejo das acadêmicas de quererem saber mais a respeito de seus futuros compromissos/funções/ações na escola no papel de Coordenadoras Pedagógicas.

\section{Metodologia}

Cada grupo recebia uma temática, definida previamente e coletivamente para pesquisar. $\mathrm{O}$ estudo era direcionado por um problema de pesquisa e um objetivo. O número de grupos era de acordo com o número de temas. A sala se transformava em uma "escola" e quem apresentava os estudos eram consideradas as "Coordenadoras Pedagógicas daquela escola”. As origens das temáticas sempre estiveram atreladas às observações que faziam na prática escolar como monitoras ou auxiliares de sala. As dificuldades sentidas ao trabalharem junto aos professores regentes transformavam-se em problemas para a própria pesquisa.

Contudo, uma questão era esclarecida às alunas: “[...] o coordenador vive crise de identidade" (SERPA, 2011, p. 14). O referido autor afirma que no cotidiano escolar, os CPs realizam tarefas diferentes de uma das suas funções essenciais, a formação docente. Muitas são as vezes que grande parte de suas ações tem relações com as questões burocráticas, substituição de professores faltantes, assessoramento aos diretores, dentre outras.

Neste sentido, considerando a importância da função do Coordenador Pedagógico como o responsável pela Formação Continuada dos professores, em seu papel formador, percebia-se a necessidade de aprender a:

[...] oferecer condições ao professor para que aprofunde sua área específica e trabalhe bem com ela, ou seja, transforme seu conhecimento específico em ensino. Importa, então, destacar dois dos principais compromissos do CP: com uma formação que represente o projeto escolar [...] e com a promoção do desenvolvimento dos professores [...] imbricados no papel formativo, estão os papéis de articulador e transformador (PLACCO; ALMEIDA; SOUZA, 2011, p. 230).

Assim sendo, a cada turma revisavam-se os temas e alguns poderiam ser incluídos e/ou substituídos por outros, dependendo das experiências das turmas. No segundo semestre 
de 2016, os temas foram: O coordenador pedagógico e sua identidade profissional; Os desafios da educação inclusiva com foco nas redes de apoio; Perspectivas atuais da educação; As relações interpessoais entre os professores; Projeto político-pedagógico e o papel da equipe gestora: dilemas e possibilidades; Estratégias para a inclusão do aluno com necessidades educacionais especiais no ensino regular; $\mathrm{O}$ processo de escolha de livros didáticos; A diversidade étnico-racial na escola; Metodologia da problematização; Mudando a educação com metodologias ativas; Educação em direitos humanos; Gestão Democrática da Educação e Educação para a paz.

As apresentações, sempre planejadas e orientadas pela professora da disciplina, deveriam ter: socialização do planejamento com a apresentação do plano de ação para todo o grupo; apresentação teórica fundamentada e em Power Point; apresentação de uma atividade prática articulada ao tema e ao problema dado; intervalo com um pequeno lanche oferecido às colegas, e encerrava-se com a avaliação pelos "professores" (colegas de classe) e pela professora da disciplina, com critérios conhecidos por todas.

O grupo responsável pela "Formação" do dia, era avaliado desde a recepção a todos os envolvidos, até a realização da atividade prática com suas colegas de turma.

\section{Resultados}

De uma forma bem sucinta pode-se dizer que as alunas, em todas as versões, ao terminar o Projeto reconheciam o papel do Coordenador Pedagógico na escola pública como

[...] um dos agentes de mudança das práticas dos professores mediante as articulações que realiza entre estes, num movimento de interações permeadas por valores, convicções, atitudes; e por meio de suas articulações internas, que sua ação desencadeia nos professores, ao mobilizar suas dimensões políticas, humano interacionais e técnicas, reveladas em sua prática (ORSOLON, 2006, p. 20).

A sensação de "agentes de mudança" era substituída pelo pânico que sentiam no início do Projeto. Após as "Formações" sentiam-se mais conhecedoras e mais experientes para iniciarem ou transformarem suas práticas pedagógicas, no caso especificamente, suas práticas de Coordenadoras Pedagógicas.

Em todas as turmas da experiência uma fala sempre estava presente: "professora, todas as nossas aulas deveriam ser assim. Aprendemos muito mais desta forma e sentimos passar por um curso sem maiores discussões a respeito dos temas estudados agora com o Projeto".

No que se refere ao processo de autorregulação da prática docente da professora da disciplina, ressalta-se que esta se realizou pelas avaliações efetuadas por todas as turmas, a cada versão do projeto. Durante as apresentações, enquanto anotava o que deveria ser retomado em termos de conhecimentos (conceitos) e comportamentos, a professora também registrava os pontos fracos, para transformá-los em pontos fortes na próxima versão do Projeto. A cada versão, mudanças ocorriam a partir, tanto da observação da professora,

\begin{tabular}{l|l|l|l|l|l|l} 
(C) Rev. Inter. Educ. Sup. & Campinas, SP & v.2 & n.3 & p.532-551 & set./dez. 2016 & ISSN 2446-9424
\end{tabular}


quanto das observações das alunas.

A avaliação sempre foi muito clara e com muito cuidado para não deixar o próximo grupo mais tenso do que naturalmente já estavam. O combinado era de que nas apresentações que se seguiam, não poderiam ocorrer os mesmos erros cometidos. Assim, a autorregulação tanto era para o ensino quanto para a aprendizagem. Isto influenciava, obviamente o planejamento das próximas versões.

Neste sentido, foi possível confirmar que a autorregulação da prática docente apresenta diversas vantagens: para a docência, para a formação das futuras professoras, para quem elas formarão e para a sociedade de um modo geral.

\section{Caso 4 - Professora $S$}

\section{Contextualização}

O caso da Professora S foi realizado ao final da disciplina Prática Docente: Projetos Integrados, do Núcleo das Licenciaturas, da Universidade do Vale do Itajaí, em vários períodos semestrais dos anos de 2010/2012.

\section{Experiência realizada}

A experiência realizada visava obter dados para reformulação do plano de ensino no semestre seguinte, com referência aos conteúdos, metodologia e avaliação do referido plano e da prática pedagógica realizada e, tinha em vista saber o que os acadêmicos parabenizavam, criticavam e sugeriam na disciplina. Esses três tópicos, mais especificamente os dois últimos, foram utilizados, tendo em vista a busca de subsídios para a avaliação da disciplina como autorregulação docente nos processos de ensino e de aprendizagem. Tendo por base Boruchovitch (2014), o caminho pensado foi de que o acadêmico é importante no processo de ensino e de aprendizagem e que a proposta seria mais um dos itens que o conscientizaria sobre a autorreflexão. Por outro lado, a professora, com essa atitude, colocou-se, também, numa posição de estudante, que precisa aprender com os acadêmicos, visando a melhoria de seus procedimentos estratégicos e avaliativos.

Ao final, solicitava-se uma autoavaliação, tendo por base cinco itens: frequência e participação, desempenho na disciplina em termos de estudo e dedicação, compromisso e comprometimento com a disciplina. Em ambos os casos, havia uma emissão de nota.

\section{Metodologia}

A metodologia para solicitar a avaliação da disciplina e da autoavaliação tinha por base um preparo anterior, registrando sobre a importância da ação, bem como toda uma argumentação responsável e consciente dos dados que seriam registrados na ficha de avaliação (Apêndice C). Solicitava-se uma crítica real sobre os itens solicitados na respectiva ficha, pois eles seriam subsidiadores para o semestre seguinte da disciplina. Explicitava-se

\begin{tabular}{l|l|l|l|l|l|l} 
(C) Rev. Inter. Educ. Sup. & Campinas, SP & v.2 & n.3 & p.532-551 & set./dez. 2016 & ISSN 2446-9424
\end{tabular}


sobre a necessidade da colaboração que estariam efetuando para o aperfeiçoamento da disciplina, bem como a qualidade de serviços que a cada semestre estava sendo prestado.

\section{Resultados}

Os resultados da tabulação serviam para verificar o que gostavam, reforçando a continuidade ou não da programação. Mas, o que efetuavam de críticas e sugestões eram levadas em consideração, objetivando reformulações, ampliações ou supressões a partir do conjunto de dados. Geralmente, esses itens tinham direção no campo das atividades realizadas, com proposições de outras ou reformulação da efetuada. Já os subsídios da autoavaliação do acadêmico serviam para visualização de como ele se via na disciplina, tendo por base cinco itens já referenciados. Geralmente, a nota da professora, referente a esses itens, já havia sido emitida e, esses dados serviam para balizar com acréscimos ou manutenção da pontuação já efetuada. A professora, por princípio, não decrescia a pontuação, tendo em vista a autoavaliação. Os dados, geralmente, incidiam em problemas de autoestima muito baixa ou muito alta: os alunos estudiosos, dedicados e esforçados na disciplina emitiam notas inferiores ao que o professor registrava e aqueles alunos um tanto regulares na disciplina se davam notas superiores. As explicações desses alunos chamavam atenção, principalmente quando questionados. Elas eram muito banais e sem fundamento e sem noção pessoal, como por exemplo: "eu tenho que me valorizar, professora, senão.... quem vai fazer isso"; "eu me considero assim"; "assim que eu me vejo, professora" e outras do gênero.

Pode-se dizer que para a professora da disciplina, os resultados dessa ficha de avaliação, em grande parte, foram levados em consideração o que permitiu uma aproximação, interação e integração maior com essa juventude do ensino superior. Foi uma exercitação de como a professora tornou-se, também, uma "estudante autorregulado, como diz Boruchovitch (2014). O desempenho da professora e a forma de se achegar aos acadêmicos foram, gradativamente, melhorando e aperfeiçoando, repercutindo positivamente na disciplina. Os subsídios oriundos da tabulação revelaram que, muito pouco foram em relação à troca de conteúdo. Os resultados incidiram mais em relação tipos de metodologia, atividades, procedimentos, prazos e avaliações realizadas. Gradativamente, a docente levou em consideração várias proposições, sugestões e atitudes propostas, que auxiliaram na forma de trabalhar com a faixa etária. Isto tudo acabou repercutindo nos itens da ficha de avaliação da docente institucional. Levar em conta a opinião dos acadêmicos só trouxe benefícios, o que permitiu depois de tantos anos de trabalho, "entrar um pouco na onda" desses jovens universitários cheios de vida e de energia, que tanto falam em aula dinâmica.

\section{Conclusões}

Infere-se que as experiências sobre avaliação como autorregulação docente nos processos de ensino e de aprendizagem do ensino superior têm sido pouco socializadas. $\mathrm{O}$ uso mais frequente é de direcionar e estimular o acadêmico, no sentido de ele vir a praticar a 
autorregulação desde os primeiros períodos universitários. Estimular a independência e a autonomia intelectual dos acadêmicos é meta dos docentes universitários, via autoavaliação das ações e dos processos.

As experiências de avaliação como autorregulação docente relatadas, neste artigo, estimularam o pensar, o saber e o fazer da prática docente nas respectivas disciplinas em que ocorreram as experiências dos docentes do grupo, possibilitando rever, repensar, refletir, dar novo sentido e significado, redimensionando atividades, processos e metodologias de trabalho docente no Ensino superior.

As pesquisadoras do grupo GEPES/UNIVALI fizeram uso do Mapa Conceitual, como ressignificação da estratégia no trabalho da disciplina; de Projetos Integrados, como motivador, visando à superação das dificuldades que os acadêmicos enfrentavam; de Simulação da Função de Coordenador Pedagógico como formador de professores nas escolas de Educação Básica, realizada por meio de estudos de temáticas atuais e necessárias à formação docente; da contribuição de como os alunos percebiam a disciplina e a sua atuação no final do período, visando contribuir para melhoria da qualidade e dos serviços da mesma para o semestre seguinte.

A avaliação das diversas ações e estratégias diversificadas, diferentes e criativas, oportunizou a autorregulação da prática docente, bem como, contribuiu significativamente para a autoavaliação dos acadêmicos sobre as experiências, propiciando ajustes e melhorias nas disciplinas com resultados significativos visíveis e de transformação a cada novo semestre em que as professoras ministraram a disciplina. Trazer o aluno, objetivando seu maior envolvimento, participação, motivação e interação na disciplina resultou em melhoria nos resultados, no rendimento acadêmico e, principalmente, no redimensionamento da prática pedagógica do docente.

\section{Referências}

BORBA, Amândia Maria de; FERRI, Cássia. Avaliação: contexto e perspectivas. In:

CAPELLETTI, Isabel (Org.). Avaliação educacional: fundamentos e prática. São Paulo: Ed. Articulação Universidade/Escola, 1999.

BORBA, Amândia Maria de; FERRI, Cássia; HOSTINS, Regina Célia Linhares. Avaliação da aprendizagem no ensino superior: questões que emergem da prática docente.

Contrapontos, v.7, n.1, p. 43-54, jan./abr. 2007.

BORGES, Marcos de Carvalho. Carlos H. Miranda, Rodrigo C. Santana, Valdes R. Bollela. Avaliação formativa e feedback como ferramenta de aprendizado na formação de profissionais da saúde. Medicina, Ribeirão Preto, v. 3, n. 47, p. 324-331, 2014.

BORGES, Tegilson Maciel. Curso: Didática e Metodologia do Ensino superior (UMC). Disponível em http:// slideplayer.com.br/slide/385113/. Acesso em: 29 mar. 2015. 
BORUCHOVITCH, Evely. Autorregulação da aprendizagem: contribuições da psicologia educacional para a formação de professores. Revista Quadrimestral da Associação Brasileira de Psicologia Escolar e Educacional, São Paulo, v. 18, n.3, set./dez, 2014.

BRASIL. Palácio da Presidência. Lei 9394 de 20 de dezembro de 1996. Estabelece as diretrizes e bases da educação nacional. Disponível em:

<https://www.planalto.gov.br/ccivil_03/Leis/L9394.htm>. Acesso em: 14 nov. 2016.

CORTELLA, M.S. A ética e a produção do conhecimento hoje. Disponível em: <http://www.apropucsp.org.br/revista/r27_r05.htm.>. Acesso: 26 maio 2008.

COSTA, Sônia da. Avaliação formativa: metodologias e instrumentos. Curso de Formação de Avaliadores: Rede CERTIFIC. Disponível em: <https://www.ifb.edu.br/... 201052415162311. Certific-avaliacao_formativa>. Acesso em: 10 mar. 2015.

DESPRESBITERIS, Léa. Avaliação da aprendizagem do ponto de vista técnico-científico e filosófico-político. Disponível em: <http://www.crmariocovas.sp.gov.br/pdf/ideias_ 08_p161-172_c.pdf>. Acesso em: 08 mar. 2016.

FERNANDES, Domingos (coord.). Avaliação criterial//Avaliação normativa. In: PENSAR avaliação, melhorar a aprendizagem. Lisboa: IIE, 1994. Disponível em <http://www. dge.mec.pt/sites/default/files/Secundario/ Documentos/Avaliacao/avaliacao_criterial.pdf>. Acesso em: 15 nov. 2016.

FERNANDES, Domingos. O papel da avaliação formativa alternativa na concepção e desenvolvimento curriculares. Sessão de Trabalho na Universidade de Caxias do Sul (RS), Brasil, 18 nov. 2005. Disponível em: <http:/www.ucs.br/ucs/tplInstitucional/graduacao/ foruns/coordenadores/apresentacao/18nov.ppt>. Acesso em: 12 abr. 2012.

FERREIRA, Carlos Alberto. Analisando Práticas de Auto-Avaliação de Alunos do $1^{\circ}$ Ciclo do ensino Básico Português. In: CONGRESSO INTERNACIONAL GALEGOPORTUGUÊS DE PSICOPEDAGOGIA, 10., 2009, Braga. Actas do... Braga: Universidade do Minho, 2009. p. 3501-3514.

FLAVELL, J. Metacognition and cognitive monitoring: A new area of cognitive developmental enquiry. American Psychologist, v.34, p. 906-911, 1979.

HADJI, Charles. Avaliação desmistificada. Porto Alegre: Artmed, 2001.

HAYDT, Regina Célia C. Curso de didática geral. 8.ed. São Paulo: Ática, 2006.

KRAEMER, Maria Elisabeth. A avaliação de aprendizagem como processo construtivo de um novo fazer. Avaliação: Rede de Avaliação Institucional da Educação Superior - RAIES, Campinas, v.10, n.2, p. 137-147, jun. 2005.

KUROSHIMA, Kátia Naomi et al. Formação continuada para docentes do ensino superior da Universidade do Vale do Itajaí: o olhar de formadoras do GEPES/UNIVALI. Revista Internacional de Educação Superior, v.2, n.2, p. 366-381, maio/ago 2016.

LUCKESI, C. Planejamento e avaliação na escola: articulação e necessária determinação ideológica. In: Avaliação da aprendizagem escolar. São Paulo: Cortez, 1995.

\begin{tabular}{l|l|l|l|l|l|l} 
(C) Rev. Inter. Educ. Sup. & Campinas, SP & v.2 & n.3 & p.532-551 & set./dez. 2016 & ISSN 2446-9424
\end{tabular}


LUZ, Sueli Petry da; BORBA, Amândia Maria de (Coord.). UNIVALI - Universidade do Vale do Itajaí: apontamentos para novas alternativas pedagógicas. Itajaí: UNIVALI, 2001.

LUZ, Sueli Petry da; BORBA, Rosangela Aparecida. Feedback na avaliação formativa no ensino superior. Itajaí: Especialização em Formação Contemporânea para o Ensino na Área da Saúde, 2015. (mimeo).

MIRANDA, Eliana C.M.; SOBREIRO, Maria Aparecida; VERGÍLIO, Maria Silvia T.G. Revisitando os conceitos e a história: entendendo as lógicas do campo da avaliação. In:

SEMINÁRIO AVANÇADO DE AVALIAÇÃO. Campinas: Faculdade de Educação, 2003. (mimeo).

\section{MOREIRA, Marco Antonio; BUCHWEITZ, Bernardo. Novas estratégias de ensino e aprendizagem: os mapas conceptuais e o vê epistemológico. Lisboa: Plátano, 1993.}

ORSOLON, Luzia A. M. O coordenador/ formador como um dos agentes de transformação da/na escola. In: ALMEIDA, Laurinda Ramalho de; PLACCO, Vera Maria Nigro de Souza (Org.). O coordenador pedagógico e o espaço de mudança. 5.ed. São Paulo: Loyola, 2006.

PERRENOUD, Philippe. Avaliação: da excelência à regulação das aprendizagens - entre duas lógicas. Porto Alegre: Artes Médicas Sul, 1999.

PLACCO, Vera Maria Nigro de Souza; ALMEIDA, Laurinda Ramalho de; SOUZA, Vera Lucia Trevisan de (Coord.). O coordenador pedagógico e a formação de professores: intenções, tensões e contradições. In: FUNDAÇÃ̃O VITOR CIVITTA. Estudos \& pesquisas educacionais. São Paulo: Abril, 2011. Disponível em: <http://www.fvc.org.br/pdf/livro2-04coordenador.pdf >. Acesso em: 21 nov. 2016.

SÁ, Susana Oliveira; ALVES, Maria Palmira; COSTA, António Pedro. O contributo do feedback na avaliação das aprendizagens no ensino superior: Implicações no desempenho dos estudantes. In: ATAS CIAIQ2014: investigação qualitativa em educação. Disponível em: $<$ http://proceedings.ciaiq.org/index.php/CIAIQ/article/view/373/370 >. Acesso em: 18 fev. 2016.

SANTOS FILHO, José Camilo dos. Avaliação da sala de aula: conceito, propósitos, características e implantação. In: WORKSHOP USP, 2013, São Carlos. Disponível em <http://www.prg.usp.br/wp-content/uploads/avaliação-J.-Camilo-S.-Filho.ppt>. Acesso em: $27 \mathrm{fev} ; 2016$.

SERPA, Andréa. Avaliação: de que? de quem? para que? para quem? Rio de Janeiro: Universidade Federal Fluminense, [s.d.]. Disponível em: $<$ http://slideplayer.com.br/slide/ 379098/>. Acesso em: 05 mar. 2015.

SERPA, Dagmar. Coordenador pedagógico vive crise de identidade. In: Os caminhos da coordenação pedagógica e da formação de professores. São Paulo, Fundação Victor Civita, n.6, ed. esp., jun. 2011.

SOUSA, Eda C. B. Machado (Org.). Mapas de informação. Brasília: Universidade de Brasília; Faculdade IESB, Instituto de Educação Superior de Brasília, 1999. (Curso de Especialização e Educação Continuada em Avaliação Institucional e a Distância). 
VALE, Susana Margarida Marques do. A transição de um paradigma tradicional para uma avaliação autêntica das aprendizagens: uma cultura avaliativa em que os objetivos e os processos de ensino, aprendizagem e avaliação são interdependentes. Porto: Universidade Católica Portuguesa: Disponível em: <http://www.meloteca.com/pdf/susana-vale_avaliacaoreflexao-2.pdf $\geq$. Acesso em: 06 nov.2016.

\section{APÊNDICE A}

Fichas de Avaliação utilizadas pela professora Y para autoavaliação discente no desenvolvimento do Mapa Conceitual e seu uso como instrumento autorregulatório da disciplina.

\begin{tabular}{|c|c|c|c|}
\hline \multicolumn{2}{|l|}{ Parâmetros para autoavaliação } & \multicolumn{2}{|c|}{$\begin{array}{c}\text { Seu } \\
\text { posicionamento }\end{array}$} \\
\hline \multicolumn{4}{|l|}{ Como você começou a estruturar o mapa conceitual? } \\
\hline \multicolumn{4}{|l|}{ Quais foram as facilidades que você encontrou na primeira elaboração do MC? } \\
\hline \multicolumn{4}{|l|}{ E, as dificuldades - qua(l)is você encontrou? } \\
\hline \multicolumn{4}{|l|}{ O que você fez para superar as dificuldades? } \\
\hline \multicolumn{4}{|l|}{$\begin{array}{l}\text { Quantas vezes você (re)elaborou o MC? Quais razões levaram você decidir por } \\
\text { (re)elaborar? }\end{array}$} \\
\hline \multicolumn{4}{|l|}{ Você estabeleceu algum(ns) critério(s) para começar a elaborar o seu MC? Qual(is)? } \\
\hline \multicolumn{4}{|l|}{ E, o que você levou em consideração para interrelacionar os conceitos? } \\
\hline \multicolumn{4}{|l|}{$\begin{array}{l}\text { O MC possibilitou você identificar conceitos/ideias que já conhecia? E aqueles que } \\
\text { você não conhecia o significado? }\end{array}$} \\
\hline \multicolumn{4}{|l|}{ O que você aprendeu durante o processo de elaboração do mapa? } \\
\hline CRITÉRIOS de AUTOAVALIAÇÃO - Mapa Conceitual & Sim & $\begin{array}{c}\text { Em } \\
\text { parte }\end{array}$ & Não \\
\hline \multicolumn{4}{|l|}{ 1. Apresenta os conceitos/ideias essenciais apresentados no texto discutido } \\
\hline \multicolumn{4}{|l|}{ 2. Os conceitos parcelares articulam-se com os essenciais } \\
\hline \multicolumn{4}{|l|}{ 3. As relações entre os conceitos são justificadas } \\
\hline \multicolumn{4}{|l|}{ 4. O conteúdo tem representatividade em relação ao discutidos pelo autor } \\
\hline \multicolumn{4}{|l|}{ 5. Realizei pesquisa quando não conhecia o significado de termos/conceitos } \\
\hline \multicolumn{4}{|l|}{ 6. Questionei as dúvidas durante a elaboração do MC } \\
\hline \multicolumn{4}{|l|}{ 7. Busquei ser criativo na representação conceitual } \\
\hline Nota final & & & \\
\hline
\end{tabular}

\section{APÊNDICE B}

Ficha de Avaliação utilizada pela professora K para autoavaliação discente sobre a sua participação no Projeto Integrador e seu posterior uso como ferramenta autorregulatória na disciplina.

\section{AUTOAVALIAÇÃO DA ATIVIDADE PROJETO INTEGRADOR}

Ler atentamente as questões sobre a autoavaliação da disciplina, refletir e responder. Considerar o comportamento ao longo de todo o semestre. Ao final do questionário, inserir uma nota para a autoavaliação. Esta nota será a nota da questão 7 da PE4. 


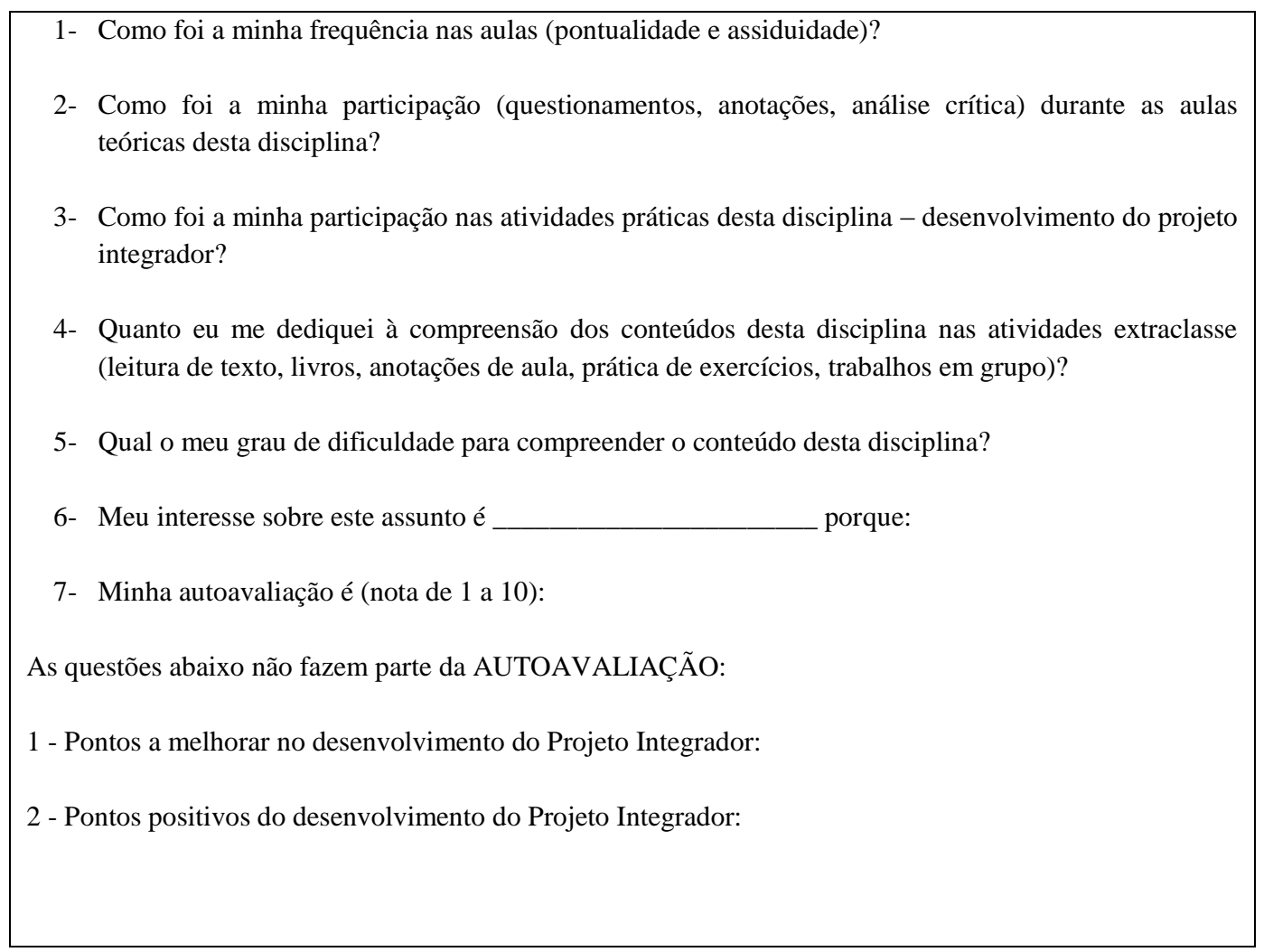

\section{APÊNDICE C}

A ficha de avaliação utilizada pela professora S na Disciplina de Prática Docente: Projetos Integrados, Do Núcleo Das Licenciaturas, da Universidade do Vale do Itajaí - UNIVALI. Esta ficha foi repassada pela professora W, do Núcleo de Licenciaturas, de quem é a referência.

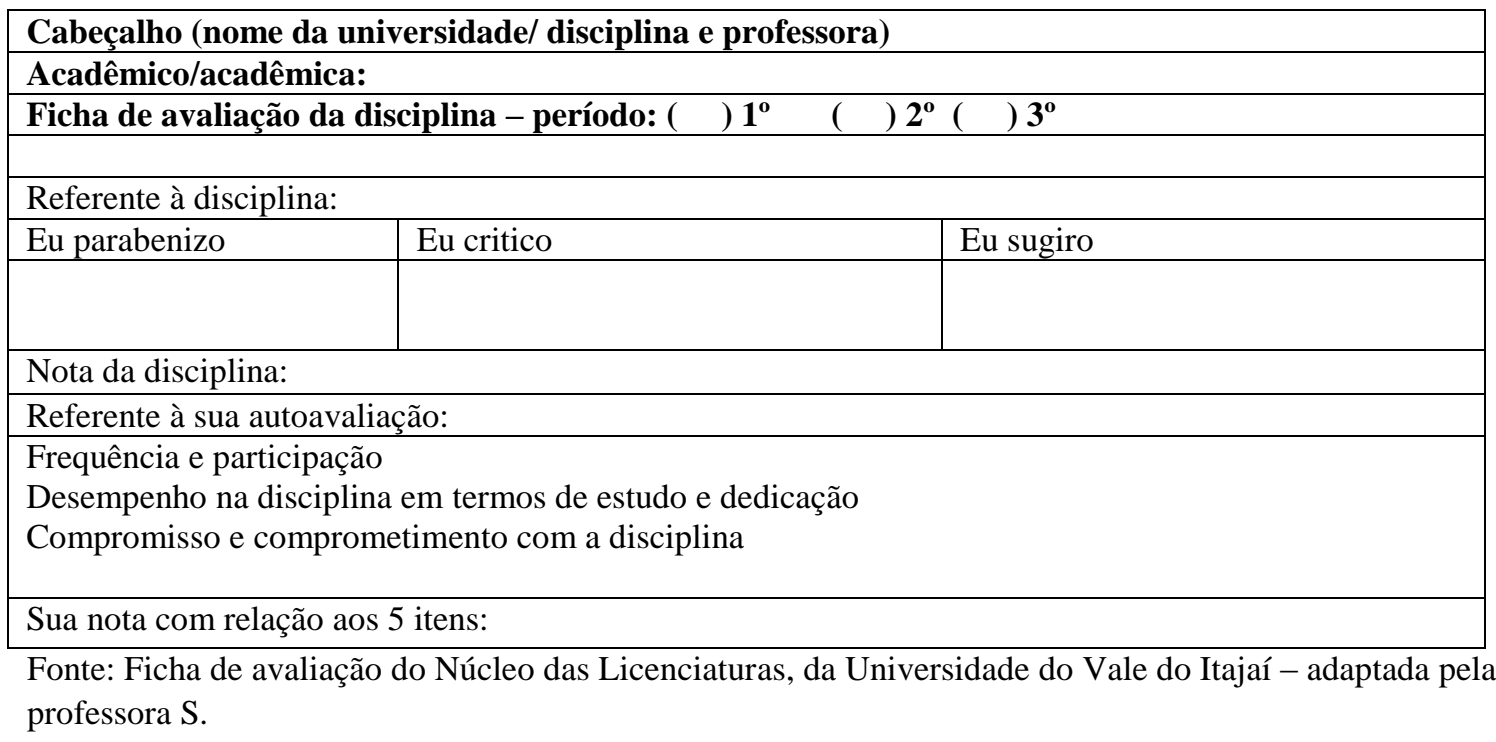

